\title{
Geoquímica das águas do reservatório Poção da Ribeira, Agreste Central de Sergipe
}

Waters's geochemistry of the Poção da Ribeira reservoir, Central Agreste of Sergipe State

\author{
C. E. O. Santos ${ }^{1 *}$; J. S. Peixoto ${ }^{2}$; J. P. H. Alves ${ }^{3}$ \\ ${ }^{I}$ Companhia de Saneamento de Sergipe - DESO, CEP. 49.020-380, Aracaju-SE, Brasil \\ ${ }^{2}$ Doutorado em Saúde e Ambiente - PSA, Universidade Tiradentes - UNIT, CEP. 49.032-490, Aracaju - SE, \\ Brasil \\ ${ }^{3}$ Programa de Pós-graduação em Recursos Hídricos - PRORH, Universidade Federal de Sergipe - UFS, CEP. \\ 49.100-000, São Cristóvão - SE, Brasil
}

*ceduquim@gmail.com

(Recebido em 29 de maio de 2017; aceito em 08 de outubro de 2017)

\begin{abstract}
Nesse trabalho foi avaliada a qualidade da água do reservatório Poção da Ribeira, em relação à dominância iônica e suas características para uso na irrigação. O reservatório foi construído pelo governo do estado de Sergipe, com o objetivo de fornecer água ao perímetro irrigado Poção da Ribeira e entrou em operação no ano de 1987. Atualmente, também utilizado para a piscicultura e abastecimento humano, após tratamento. Foi elaborado um plano de coleta de amostras de água superficial, levando-se em consideração a distribuição das chuvas para a região (períodos secos e chuvosos), totalizando sete campanhas amostrais distribuídas nos anos de 2013, 2014 e 2015, sendo uma amostra de água para cada campanha. Em cada amostra foram analisados os seguintes parâmetros: condutividade elétrica, sódio, potássio, cálcio, magnésio, cloreto, sulfato e bicarbonato. Para a avaliação da dominância iônica foi utilizada a técnica de balanço iônico, realizada através da ferramenta geoquímica gráfica denominada diagrama de Piper. A característica da qualidade para o uso na irrigação foi verificada utilizando-se a metodologia proposta por Richards, por meio do diagrama de Wilcox. Nos períodos chuvosos as águas foram classificadas, predominantemente, como mistas/cloretadas e as estações secas como sódicas/cloretadas, demonstrando a influência das precipitações na composição química das águas. Quanto ao uso para irrigação, a avaliação revelou baixo risco de sodicidade e risco médio de salinização. Palavras chave: Composição iônica, diagramas hidroquímicos, salinização.
\end{abstract}

In this work the water quality of the Poção da Ribeira reservoir was evaluated in relation to the ionic dominance and its characteristics for use in irrigation. The reservoir was built by the state government of Sergipe, with the purpose of providing water to the Poção da Ribeira irrigated perimeter and started operating in 1987. Currently, it is also used for fish farming and human supply after treatment. A plan was drawn up to collect surface water samples, taking into account the distribution of rainfall to the region (dry and rainy periods), totalling seven sample campaigns distributed in the years of 2013, 2014 and 2015, being a sample of water for each campaigns. In each sample were analysed the following parameters: electrical conductivity, sodium, potassium, calcium, magnesium, chloride, sulphate and bicarbonate. For the evaluation of ionic dominance, the ionic balance technique was used, using the graphical geochemical tool called the Piper diagram. The quality characteristic for use in irrigation was verified using the methodology proposed by Richards, using the Wilcox diagram. In the rainy periods the waters were predominantly classified as mixed / chlorinated and the dry seasons as sodium / chlorinated, demonstrating the influence of precipitation on the chemical composition of the waters. Regarding the use for irrigation, the evaluation revealed low risk of sodicity and average risk of salinization.

Key words: Ionic composition, hydrochemical diagrams, salinization.

\section{INTRODUÇÃO}

Reservatórios de regularização são sistemas aquáticos modificados, construídos pelo barramento artificial de um vale natural e/ou pela formação artificial de lagos com vazões defluentes sujeitas a controle. A implantação destes reservatórios modifica a permanência das 
vazões nos rios e altera a garantia do suprimento de água a jusante, fazendo destes empreendimentos, alternativas importantes para o suprimento de água bruta às cidades e a agricultura irrigada [1, 2 e 3].

Em reservatórios de regularização, o excedente hídrico escoado nos eventos pluviométricos por meio da bacia de drenagem é reservado para posterior disponibilização, porém, por ser a água um solvente quimicamente ativo, as interações desta com as mais diversas superfícies que tem contato são responsáveis pela sua constituição química.

Dentre os principais mecanismos controladores da composição química das águas superficiais estão os fenômenos físicos e químicos do intemperismo de rochas [4 e 5]. Segundo Peres Junior (2013) [6]) os processos geológicos determinam a composição das rochas e a exposição destas à superfície desencadeiam os processos de degradação química, hidrólise, oxidação, redução dentre outros. Nesses processos são originados os minerais secundários, que serão incorporados ao ambiente aquático na forma de íons solúveis [7]. De acordo Payne (1986) [8]), o conteúdo iônico das águas superficiais é determinado principalmente pelos íons maiores (cátions $\mathrm{Ca}^{+2}, \mathrm{Mg}^{+2}, \mathrm{Na}^{+}$ e $\mathrm{K}^{+}$e ânions $\mathrm{HCO}_{3}{ }^{-}, \mathrm{SO}_{4}^{-2}$ e $\mathrm{Cl}^{-}$), sendo que a variação e composição desses íons na água é influenciada pelo ambiente terrestre, pelo clima, pelo intercâmbio entre água e sedimento e pelas atividades humanas.

O objetivo primário da geoquímica é entender o comportamento dos sistemas baseados no conhecimento das suas propriedades básicas. As relações entre íons, em termos de razões matemáticas, se destacam claramente como ferramenta útil na detecção de semelhanças e diferenças entre as águas $[9,10,11$ e 12].

A análise de dados hidroquímicos pode ser realizada por meio de diferentes técnicas, cuja aplicação é função do tipo de estudo e dos resultados que se espera atingir, destacam-se dentre estas técnicas os métodos gráficos, que são ferramentas importantes para a classificação e entendimento do padrão geoquímico das águas, sendo os diagramas trilineares, que apresentam as concentrações em percentagem para cada íon analisado, uma das mais utilizadas representações para a classificação de um conjunto de dados geoquímicos [13 e 14].

Muitas vezes, sem um planejamento global adequado, os represamentos causam desperdício e degradação da qualidade da água, em virtude do aumento da concentração de espécies químicas dissolvidas, tornando - a inadequada para alguns tipos de uso, como por exemplo a irrigação, já que a adequabilidade da água para este fim é determinada pela quantidade e tipo de espécies dissolvidas [15 e 16].

$\mathrm{O}$ uso de águas ricas em sais para irrigação pode ocasionar prejuízos ao solo e ao desenvolvimento da cultura, dentre os problemas mais comuns no uso dessas águas estão a salinidade, onde há acúmulo de sais na zona radicular da cultura dificulta a extração de água, pela planta, da solução salina do solo; e a toxidade, que ocorre quando certos constituintes da água são absorvidos pela planta, causando redução na produtividade, geralmente esse problema está associado a íons específicos, como por exemplo, o cloreto e o sódio [17 e 18].

É provável que os critérios mais importantes com respeito à qualidade da água para a irrigação sejam a concentração total de sais, medida pela condutividade elétrica (CE), e a razão de adsorção de sódio (RAS), que expressa a atividade relativa dos íons sódio em reações de intercâmbio catiônico com o solo. O método de classificação das águas para propósitos de irrigação proposto pelo United States Salinity Laboratory (USSL) de Riverside, um dos mais aceitos para este fim, correlaciona esses critérios em um diagrama cartesiano, onde o eixo das abscissas é representado pela CE e o eixo das ordenadas pela RAS, também conhecido como Diagrama de Wilcox [19, 20, 21 e 22].

O reservatório Poção da Ribeira é um projeto elaborado originalmente para fornecer água ao perímetro irrigado Poção da Ribeira, que é um importante centro produtor de hortaliças do estado de Sergipe e por tanto, contribui para a sustentabilidade do progresso da região. Atualmente este manancial também é utilizado para o abastecimento das comunidades circunvizinhas, após tratamento [23]. Neste sentido o presente trabalho teve como objetivo analisar a dominância iônica das águas desse reservatório, por meio do diagrama trilinear de Piper, assim como, utilizando o método de classificação proposto pelo USSL, avaliar a sua qualidade para propósitos de irrigação. 


\section{MATERIAL E MÉTODOS}

\section{1. Área de estudo}

A área estudada encontra-se na região nordeste do Brasil, entre os municípios de Itabaiana e Campo do Brito, no território denominado Agreste Central do estado de Sergipe, como ilustrado na Figura 1. Tal território é delimitado ao norte pela bacia hidrográfica do rio Sergipe e ao sul pela bacia do rio Vaza Barris, tem como destaque a presença de açudes, bastante utilizados para a irrigação e dessedentação animal. Por localizar-se na zona de transição entre o litoral e o sertão, o clima apresenta características destes dois territórios. A transição ocorre de leste para oeste, havendo um decréscimo no volume de precipitação e quantidade de meses chuvosos, saindo assim do clima sub-úmido para o clima semiárido brando [24].

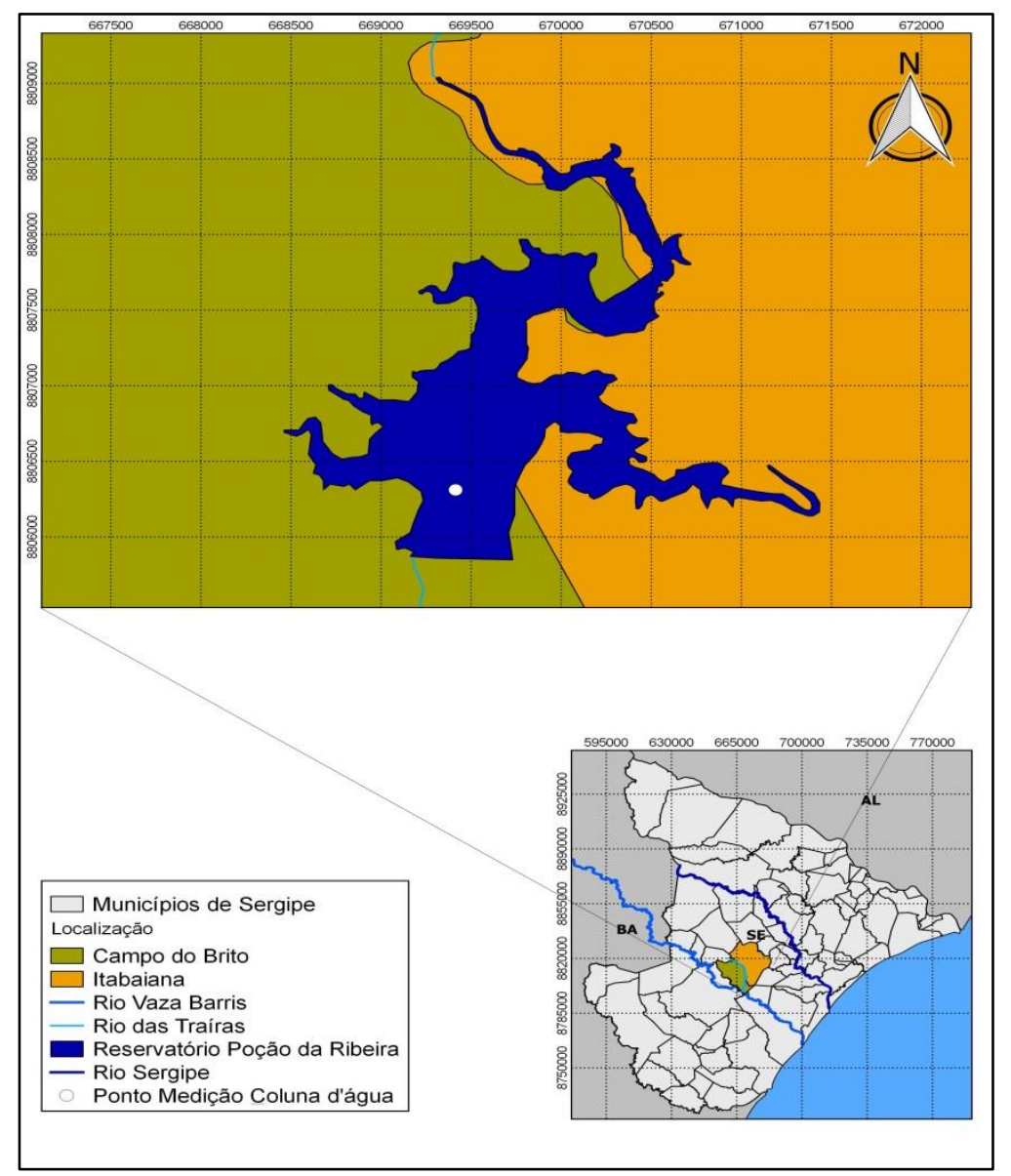

Figura 1 - Localização da área de estudo

O barramento do rio Traíras originou o reservatório Poção da Ribeira, uma barragem de terra, de seção homogênea, assente diretamente sobre rocha sã fraturada, com comprimento de $550 \mathrm{~m}$ no eixo do coroamento, de $150 \mathrm{~m}$ no vertedouro e altura $26 \mathrm{~m}$. Sua construção foi iniciada em 1985 e concluída em 1987, durante o programa do governo estadual denominado Chapéu de Couro [25], as características do reservatório estão listadas na Tabela 1. Seu propósito original foi a irrigação das terras agricultáveis do Perímetro Irrigado Poção da Ribeira, um importante centro produtor de hortaliças do estado de Sergipe, sob a coordenação da Companhia de Desenvolvimento de Recursos Hídricos e Irrigação de Sergipe (COHIDRO), que é a entidade estadual encarregada de fornecer assistência técnica aos produtores que estão nos perímetros irrigados estaduais. Atualmente as águas do reservatório também são utilizadas para a recreação, piscicultura e abastecimento humano.

A irrigação, de responsabilidade da COHIDRO, e o abastecimento humano, sob responsabilidade da Companhia de Saneamento de Sergipe - DESO, são os principais usos consultivos das águas do reservatório Poção da Ribeira. No perímetro irrigado, cerca de 506,41 ha, dos 1100 irrigáveis, utilizam a água do reservatório, totalizando 408 lotes irrigados para o ano 
2011 [26]. Neste mesmo ano o volume total captado para este propósito foi de $3.765 .070 \mathrm{~m}^{3}$. A água captada na barragem, após tratamento, é distribuída para quatro municípios da região agreste do estado de Sergipe: Itabaiana, Campo do Brito, Macambira e São Domingos, beneficiando aproximadamente quarenta e sete mil pessoas, tendo como volume total captado, para o ano de 2011, o valor de $135.520 \mathrm{~m}^{3}$ [27].

Tabela 1 - Características do reservatório Poção da Ribeira

\begin{tabular}{lc}
\hline Rio barrado & Rio Traíras \\
Material da barragem & Terra compactada \\
Cota de coroamento & $223,5 \mathrm{~m}$ \\
Extensão do coroamento & $550 \mathrm{~m}$ \\
Largura do coroamento & $5,0 \mathrm{~m}$ \\
Altura máxima & $26,0 \mathrm{~m}$ \\
Capacidade de acumulação & $16.500 .000 \mathrm{~m}^{3}$ \\
Volume morto & $1.000 .000 \mathrm{~m}^{3}$ \\
Área da bacia hidrográfica & $215 \mathrm{Km}^{2}$ \\
Área da bacia hidráulica & $250 \mathrm{ha}$ \\
Volume regularizado & $900 \mathrm{~L} / \mathrm{s}$ \\
Área inundada & $181,0964 \mathrm{ha}$ \\
\hline Fonte: Modificado de COHIDRO (2011) [26])
\end{tabular}

\subsection{Amostragem e análises químicas}

As campanhas para coleta de amostras ocorreram nos anos de 2013, 2014 e 2015, levando-se em consideração a distribuição anual de chuvas para a região, sendo escolhidos sete períodos amostrais, a saber: chuvoso e seco de cada ano estudado, denominados para este trabalho como CH13(junho), SE13(novembro), CH14(junho), SE14(novembro), CH15(julho) e SE15(novembro), respectivamente, e um período entre as estações seca do ano de 2014 e chuvosa do ano de 2015, denominado para este trabalho como INT15(maio). Todas as coletas foram realizadas em ponto único, como ilustrado na Figura 1, localizado nas seguintes coordenadas UTM: 669.368 (E) 8.806.311 (N) (datum SIRGAS 2000).

As amostras de água superficial foram coletadas, acondicionadas e transportadas ao Laboratório de Química de Água do Instituto Tecnológico e de Pesquisas do Estado de Sergipe (ITPS) de acordo com o Standard Methods for Examination of the Water and Wastewater [28]. As análises foram realizadas, seguindo as metodologias analíticas propostas por APHA (2012) [28]) e United States Environmental Protection Agency (US EPA) [29], para os parâmetros descrito na Tabela 2.

Tabela 2 - Metodologia Analítica utilizada

\begin{tabular}{ccc}
\hline Parâmetros & Técnica analítica & Método de referência \\
\hline Condutividade elétrica & Método condutimétrico & SM* 2510 B \\
Sódio & Cromatografia iônica & US EPA 300.7 \\
Potássio & Cromatografia iônica & US EPA 300.7 \\
Cálcio & Cromatografia iônica & US EPA 300.7 \\
Magnésio & Cromatografia iônica & US EPA 300.7 \\
Bicarbonato & Método titulométrico & SM* 2320 B \\
Sulfato & Cromatografia iônica & US EPA 300.7 \\
Cloreto & Cromatografia iônica & US EPA 300.7 \\
\hline
\end{tabular}

Standard Methods for Examination of the Water and Wastewater [28]

Para garantia da qualidade analítica foram usados a calibração com padrões, a análise de reagentes em branco e determinações em replicatas. O laboratório também participa regularmente de programas de proficiência e tem acreditação para alguns parâmetros.

A análise da dominância iônica foi realizada pela técnica de balanço iônico através do diagrama hidroquímico de Piper e a avaliação da qualidade da água para propósitos de irrigação foi realizada utilizando o método proposto pelo USSL [19] através do diagrama hidroquímico de Wilcox. 
Para a construção de ambos os diagramas hidroquímicos foi utilizado o software livre QualiGraf [30]. Programa desenvolvido pela Fundação Cearense de Meteorologia e Recursos Hídricos - FUNCEME, voltado para a interpretação gráfica de dados hidroquímicos.

\section{RESULTADOS E DISCUSÃO}

A maioria das águas naturais contém relativamente poucos constituintes catiônicos e aniônicos. Originalmente, os constituintes catiônicos mais abundantes são cálcio $\left(\mathrm{Ca}^{2+}\right)$, magnésio $\left(\mathrm{Mg}^{2+}\right)$ e sódio $\left(\mathrm{Na}^{+}\right)$. O potássio $\left(\mathrm{K}^{+}\right)$normalmente ocorre em menos abundância que o sódio. Os constituintes aniônicos mais comuns são o bicarbonato $\left(\mathrm{HCO}_{3}{ }^{-}\right)$e também, o sulfato $\left(\mathrm{SO}_{4}{ }^{2-}\right)$ e cloreto $\left(\mathrm{Cl}^{-}\right)$[31].

Os resultados das concentrações dos íons maiores presentes nas águas do reservatório Poção da Ribeira, no período desse estudo, estão apresentados na Tabela 3.

Tabela 3 - Dados da Qualidade da água do reservatório Poção da Ribeira para o período 2013 a 2015.

\begin{tabular}{l|ccccccc}
\hline \multirow{2}{*}{ Parâmetros } & \multicolumn{7}{|c}{ Períodos amostrais } \\
\cline { 2 - 8 } & CH.13 & SE.13 & CH.14 & SE.14 & INT.15 & CH.15 & SE.15 \\
\hline $\mathrm{CE}\left(\mu \mathrm{S} . \mathrm{cm}^{-1}\right)$ & 505,5 & 870,0 & 419,8 & 525,4 & 480,0 & 331,5 & 417,4 \\
$\mathrm{Na}^{+}\left(\mathrm{mg} . \mathrm{L}^{-1}\right)$ & 47,51 & 102,8 & 31,81 & 110,0 & 56,38 & 28,27 & 39,27 \\
$\mathrm{~K}^{+}\left(\mathrm{mg} . \mathrm{L}^{-1}\right)$ & 5,60 & 7,41 & 5,71 & 4,94 & 6,11 & 4,96 & 5,41 \\
$\mathrm{Ca}^{2+}\left(\mathrm{mg} . \mathrm{L}^{-1}\right)$ & 12,69 & 10,61 & 13,22 & 14,45 & 13,81 & 9,73 & 12,41 \\
$\mathrm{Mg}^{2+}\left(\mathrm{mg} \cdot \mathrm{L}^{-1}\right)$ & 10,73 & 12,02 & 15,08 & 17,18 & 16,95 & 10,94 & 12,77 \\
$\mathrm{HCO}_{3}^{-}\left(\mathrm{mg} . \mathrm{L}^{-1}\right)$ & 90,99 & 84,57 & 91,64 & 119,2 & 116,13 & 86,36 & 98,75 \\
$\mathrm{SO}_{4}{ }^{-2}\left(\mathrm{mg} . \mathrm{L}^{-1}\right)$ & 8,25 & 10,95 & 15,18 & 17,64 & 4,70 & 5,33 & 5,70 \\
$\mathrm{Cl}^{-}\left(\mathrm{mg} . \mathrm{L}^{-1}\right)$ & 76,13 & 165,8 & 80,62 & 156,4 & 75,65 & 48,27 & 62,45 \\
\hline
\end{tabular}

Dentre os cátions houve predominância do íon sódio $\left(\mathrm{Na}^{+}\right)$em todos os períodos amostrais, como pode ser observado na Figura 2, apresentando as concentrações mais elevadas durante os períodos secos, principalmente em SE.13 e SE.14. Cabe ressaltar que a magnitude das concentrações $\mathrm{de}^{\mathrm{Na}^{+}}$foi superior em, ao menos, duas vezes as concentrações apresentadas pelos demais cátions, demonstrando que essas são águas predominantemente sódica.

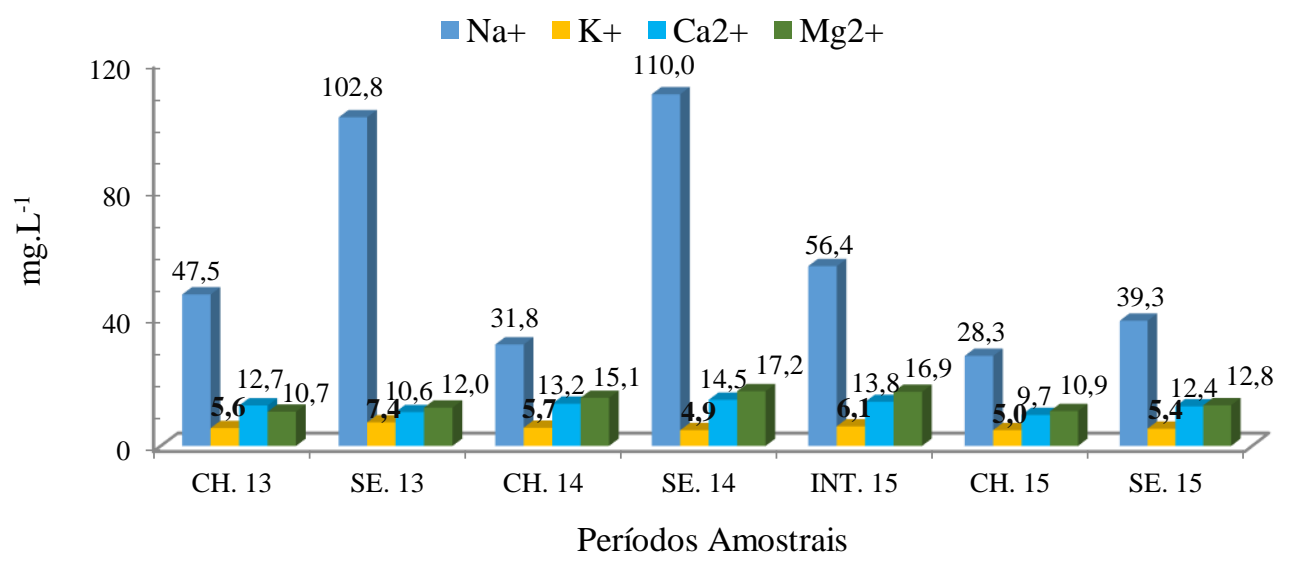

Figura 2 - Variação sazonal dos cátions nas amostras de água do reservatório Poção da Ribeira

A variação sazonal das concentrações aniônicas está apresentada na Figura 3, diferentemente do que foi observado para os cátions, onde houve predominância de um íon, observa-se a existência de uma alternância entre os íons bicarbonato $\left(\mathrm{HCO}_{3}^{-}\right)$e cloreto $\left(\mathrm{Cl}^{-}\right)$com os períodos chuvoso e seco, respectivamente, comportamento verificado nos anos de 2013 e 2014. 


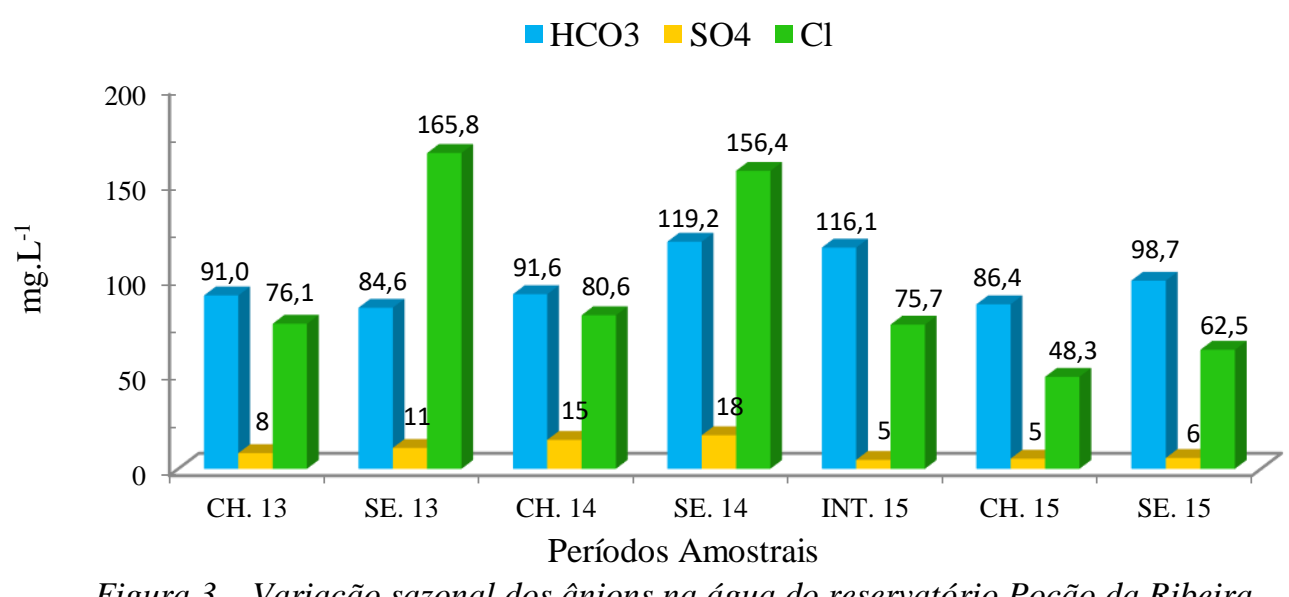

Figura 3 - Variação sazonal dos ânions na água do reservatório Poção da Ribeira

O diagrama de Piper tem sido usado como base para interpretações das propriedades hidrogeoquímica da água, é uma importante ferramenta no entendimento do padrão geoquímico e comparação de distintos grupos de águas quanto ao seu conteúdo iônico [13 e 31].

A evolução geoquímica das amostras de água do reservatório são mostradas nos diagramas trilineares de Piper das Figuras 4 (periodos chuvosos) e 5 (períodos secos). Para as amostras dos períodos chuvosos, os pontos $3(\mathrm{CH} 13)$ e $6(\mathrm{CH} 15)$ se encontram na região especificada para águas mistas, não demonstrando dominância de apenas um cátion, já para amostra do ponto 1 (CH13) a água foi classificada como sódica. Com relação à dominância aniônica observa-se que apenas para a amostra $\mathrm{CH} 15$ a água foi classificada como mista, ocorrendo águas cloretadas para as demais amostras dos períodos chuvosos. Fica evidente, portanto, que nos períodos chuvosos, as águas do reservatório no ponto amostrado, apresentaram-se predominantemente como mistas/cloretadas.

Da análise do diagrama nos períodos chuvosos infere-se que há uma tendência, principalmente em relação aos cátions, para a face mista das águas, indicando a influência das precipitações pluviométricas no aporte de sais minerais originários da bacia de drenagem, causando alterações na composição iônica das águas superficiais do reservatório no ponto de amostragem desse estudo.

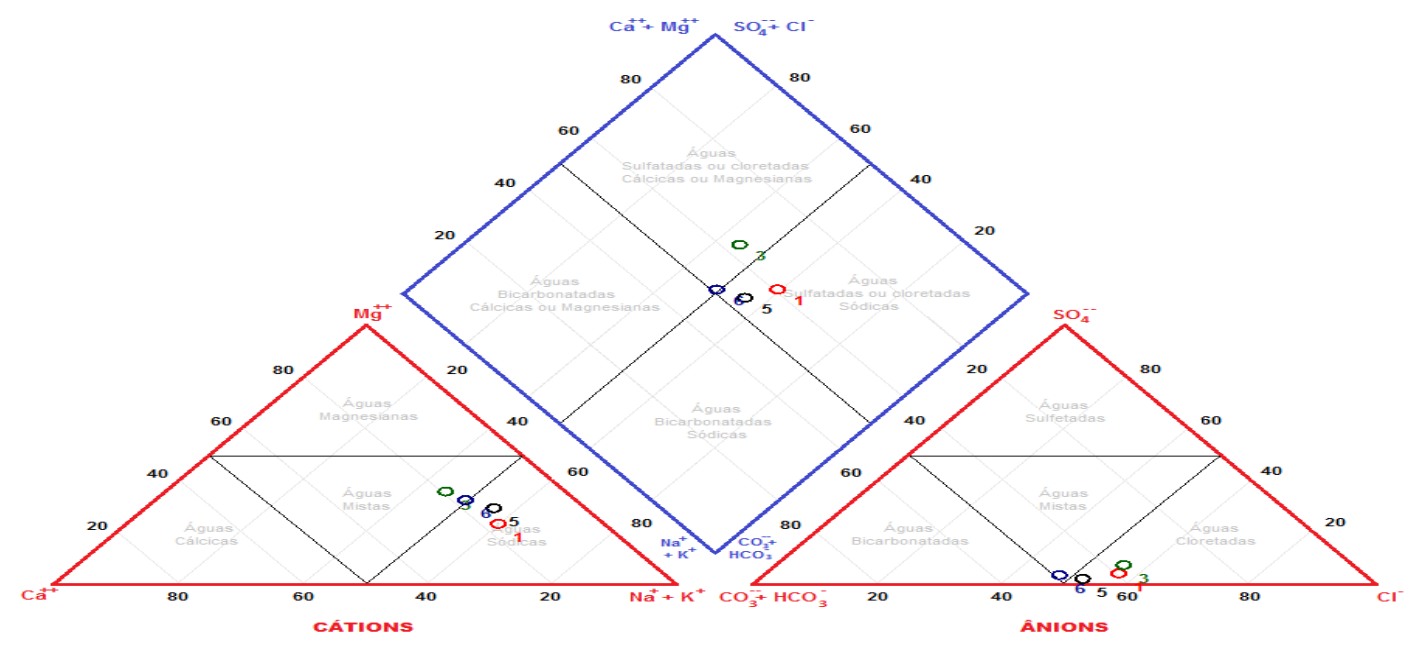

Figura 4 - Diagrama de Piper para os períodos chuvoso: 1 (CH13), 3 (CH14), 5 (INT15) e 6 (CH15)

Para os períodos secos é possível observar no diagrama de Piper (Figura 5), que todas as amostras encontram-se na região aniônica de dominância do íon cloreto e na região catiônica do íon sódio. Como observado por Lima et al. (2017) [5]), isso demonstra a predominância de águas sódicas/cloretadas nos períodos de baixa disponibilidade pluviométrica, sugerindo a possível existência de um fenômeno de troca catiônica [12], que levou as águas desse manancial, no ponto 
em estudo, a migrarem da face mista, em períodos chuvosos (CH14 e CH15), para face sódica em períodos secos (SE14 e SE15)

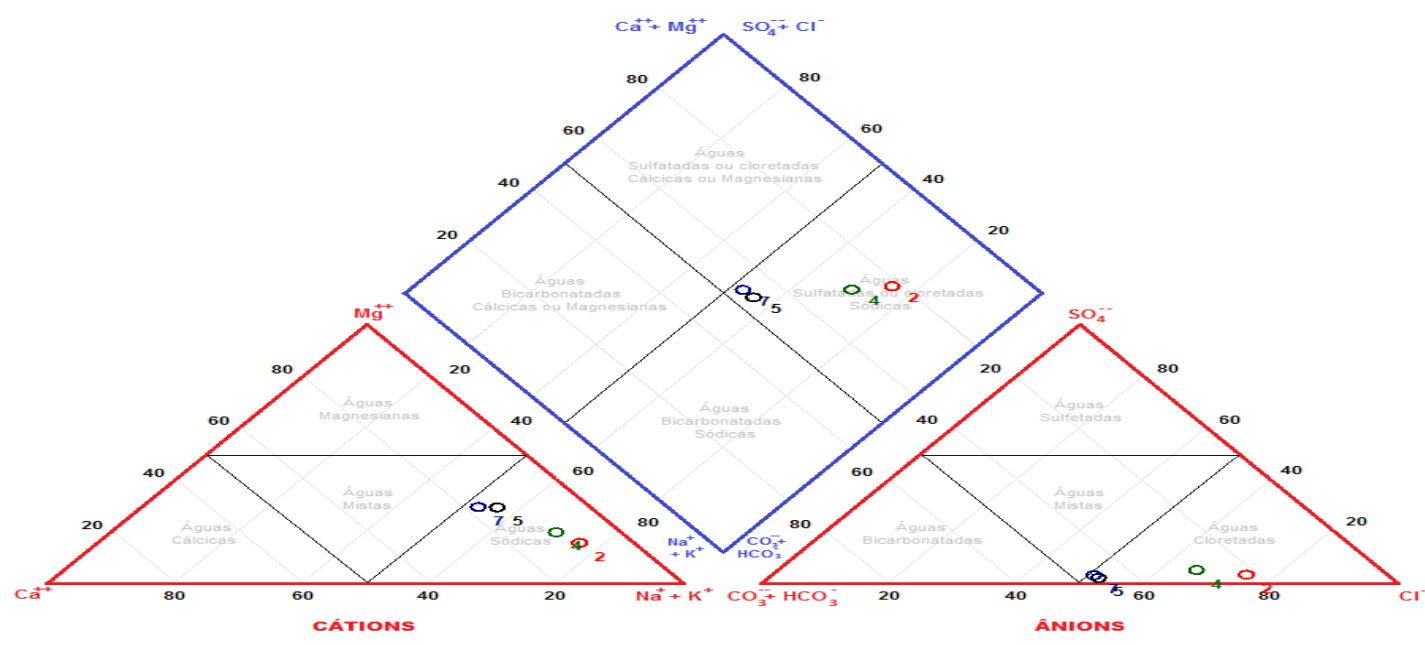

Figura 5 - Diagrama de Piper para os períodos secos: 2 (SE13), 4 (SE14), 5 (INT15) e 7 (SE15)

A predominância de águas sódicas durante os períodos secos, como destacado na Tabela 4, e considerando que a demanda de água para irrigação dos lotes agricultáveis do perímetro irrigado Poção da Ribeira, é maior nesse período, alertam para a existência de risco potencial de sodificação do solo no uso dessas águas, por isso, a qualidade para a finalidade de irrigação foi também investigada.

Tabela 4 - Dominância iônica das águas em diferentes períodos amostrais

\begin{tabular}{ccc}
\hline \multirow{2}{*}{ Períodos amostrais } & \multicolumn{2}{c}{ Classificação das águas } \\
\cline { 2 - 3 } & \multicolumn{1}{c}{ CÁTIONS } & ÁNIONS \\
\hline CH.13 & Sódica & Cloretada \\
SE.13 & Sódica & Cloretada \\
CH.14 & Mista $\left(\mathrm{Na}^{+}+\mathrm{Mg}^{2+}\right)$ & Cloretada \\
SE.14 & Sódica & Cloretada \\
CH.15 & Mista $\left(\mathrm{Na}^{+}+\mathrm{Mg}^{2+}\right)$ & Mista $\left(\mathrm{Cl}^{-}+\mathrm{HCO}_{3}{ }^{-}\right)$ \\
SE.15 & Sódica & Cloretada \\
\hline
\end{tabular}

Chama atenção a dominância iônica apresentada na estação chuvosa do ano de 2015, período de maior volume no reservatório, onde as águas apresentaram a face mista / mista, não havendo ânions ou cátions dominantes. Essa mudança na dominância iônica tem como provável causa a interação das águas pluviométricas ao longo da bacia de drenagem, aportando ao reservatório águas de composição química diferenciada das observadas nos demais períodos amostrais, principalmente em relação à composição aniônica.

Os distintos períodos amostrais foram classificados quanto ao uso para irrigação, pelo método proposto pelo USSL, conforme o diagrama apresentado na Figura 5. Os pontos inseridos no diagrama representam as amostras coletadas no período desse estudo. Verifica-se que, com exceção do ponto 2, que representa a amostra SE13, todos os demais pontos encontram-se na região de classificação $\mathrm{C} 2 \mathrm{~S} 1$, indicando risco médio de salinização $(\mathrm{C} 2)$ e baixa risco de sodicidade (S1). 


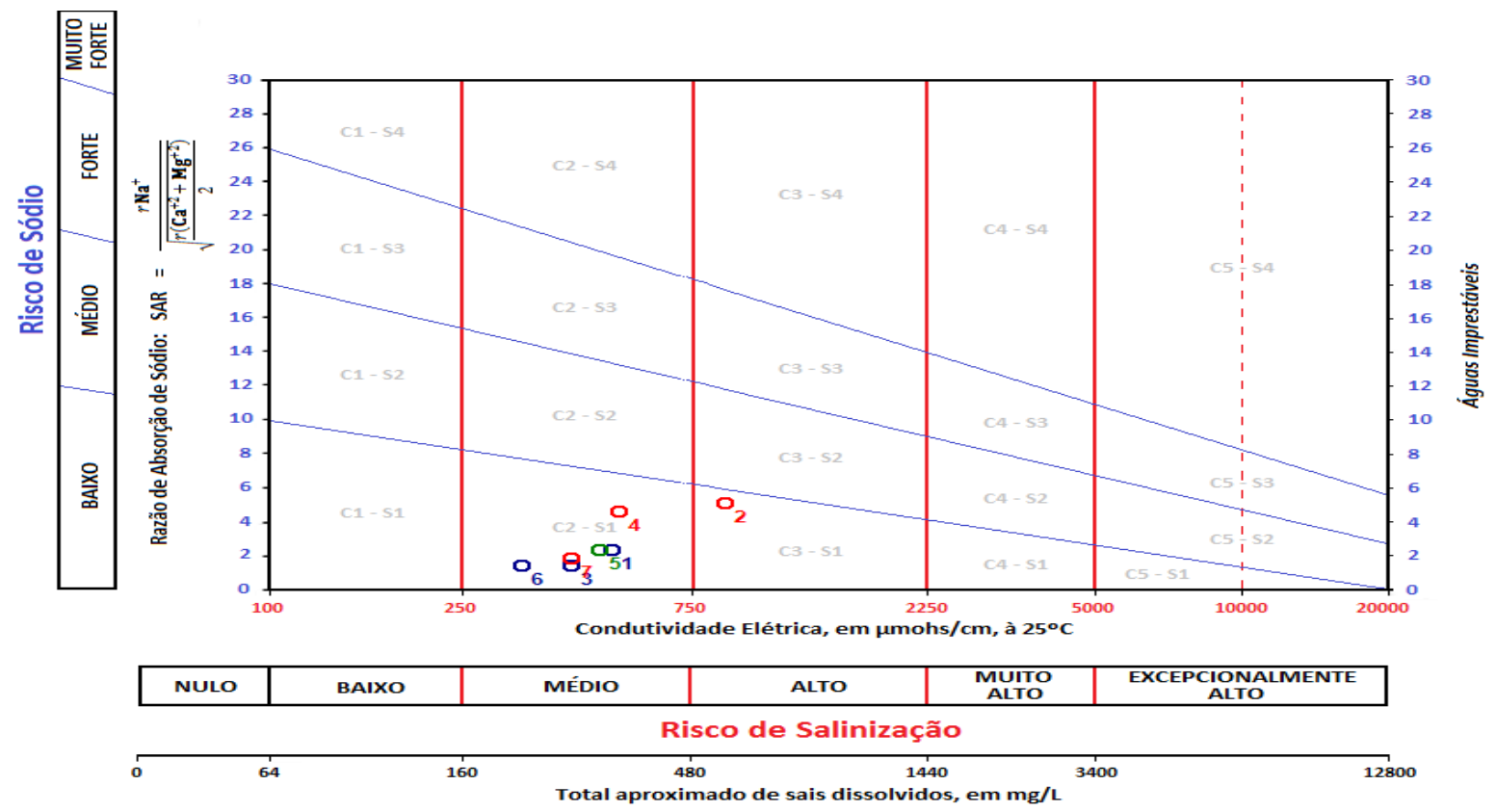

Figura 5 - Diagrama de Wilcox para classificação da água quanto ao uso para a irrigação: 1 (CH13), 2 (SE13), 3 (CH14), 4 (SE14), 5 (INT15), 6 (CH15) e 7 (SE15)

Para SE13, único ponto discordante, a classificação apresentada foi C3S1, devido ao elevado valor da CE (Tabela 3) observada para essa amostra, indicando que as águas desse período amostral apresentaram risco alto de salinização, porém apresentaram baixa sodicidade, semelhante aos demais períodos amostrais.

\section{CONCLUSÃO}

O regime de chuvas, associado aos processos de lixiviação dos solos da bacia de drenagem e a evaporação, têm influência significativa na composição e na variação sazonal dos íons presentes no ponto estudado do manancial, sendo visualizada uma provável redução na salinidade decorrente das chuvas ocorridas no ano de 2015, que elevaram as águas do reservatório ao maior nível registrado durante o período de estudo.

Os diagramas de Piper demonstram uma mudança da composição das águas nos períodos chuvosos para os secos, de águas mistas para águas sódicas, sugerindo a existência de um fenômeno de troca iônica responsável pela alternância das faces das águas, porém se faz necessário maior investigação para elucidar esse fato.

Apesar da predominância da face sódica durante as estações secas, as águas do reservatório Poção da Ribeira não apresentaram riscos de sodicidade ao solo pelo uso na irrigação, sendo classificadas como águas de baixa sodicidade (S1). Quanto ao risco de salinização, apenas um período amostral (SE13) apresentou risco alto, sendo apresentado para os demais períodos amostrais risco médio, o que alerta para a necessidade de ações de gerenciamento do reservatório visando minimizar o processo de salinização, já existente, e agravado em estiagens prolongadas.

Os resultados apresentados se aplicam à região do reservatório onde foram coletas as amostras e ao período do estudo.

\section{AGRADECIMENTOS}

Esse trabalho contou com o apoio do projeto "Monitoramento de Mananciais Superficiais e Reservatórios de Sergipe", convênio 001/2012 entre a Secretária de Estado do Meio Ambiente e Recursos Hídricos do Estado de Sergipe (SEMARH) e o Instituto Tecnológico e de Pesquisas de Sergipe (ITPS). Por isso, apresentamos os nossos agradecimentos à SEMARH e ao ITPS. 


\section{REFERÊNCIAS BIBLIOGRÁFICAS}

1. Cruz HC, Fabrizy NLP. Impactos Ambientais de Reservatórios e Perspectivas de Uso Múltiplo. Rev. Bras. Energia. 1995;4(1).

2. Prado RB. Manejo integrado de reservatórios destinados a uso múltiplo como perspectiva de recuperação da qualidade da água: Ed RiMa, São Carlos, 2004, Recursos Hidroenergéticos, usos, impactos e planejamento integrado; $346 \mathrm{p}$.

3. Asfora MC, Cririlo JA. Reservatórios de regularização: alocação de água para usos múltiplos com diferentes garantias, REGA: Rev. Gestão Águas América Latina. 2005 Jul/Dez;2(2):27-38.

4. Gibbs RJ. Mechanisms Controlling World Water Chemistry, Science. 1970 Dez;170(3962):1088-1090.

5. Lima AO, Lima-Filho FP, Dias NS, Rego PRA, Blanco FF, Neto MF. Mechanisms controlling surface water quality in the Cobras river sub-basin, northeastern Brazil. Rev. Caatinga. 2017 Jan/Mar;30(1):181-189, doi:10.1590/1983-21252017v30n120rc

6. Peres Júnior JBR. Caracterização Geoquímica e Classificação das Águas dos Rios São Bartolomeu, Couros e Tocantinzinho - Chapada dos Veadeiros, GO [dissertação]. Brasília (DF): Universidade de Brasília; 2013. 76 p.

7. Négrel P. Water-granite interaction: Clues from strontium, neodymium and rare earth elements in soil and waters. Applied Geochemistry. 2006 Aug;21(8):1432-1454, doi:10.1016/j.apgeochem.2006.04.007

8. Payne AI. The ecology of tropical lake and rivers. John Wiley and Sons. Chichester, New York, Toronto, Brisbane, Singapore; 1986. 301 p.

9. Hem JD. Study and Interpretation of the Chemical Characteristics of Natural Water. U. S. Geological Survey. Unit States; 1985. 272 p.

10. Cirelli AF, Miretzky P. Ionic realtions: a tool for studying hydrogeochemical processes in Pampean shallow Lakes (Buenos Aires, Argentina). Quartenary International. 2004;114(1):113-121, doi:10.1016/S1040-6182(03)00046-6

11. Granjeiro ML, Santiago MMF, Silva CMSV, Frischkorn H, Teixeira ZA, Mendes Filho J. Razões Iônicas e Índices de Langelier e Larson no estudo Hidrogeoquímico das Águas Subterrâneas no município de Quixeré - Ceará. In: Anais do XVIII Simpósio Brasileiro de Recursos Hídricos, 2009 Nov 22-26; Campo Grande - MS.

12. Merchán D, Auqué LF, Gimeno MJ, Causapé J. Geochemical processes controlling water salinization in an irrigated basin in Spain: Identification of natural an anthropogenic influence. Science of the Total Environment. 2015 Jan;502(1):330-343, doi:10.1016/jscitotenv.2014.09.041

13. Custódo E, Llamas MR. Hidrologia Subterrânea, $2^{a}$ Ed. Barcelona: Ediciones Omega; 1983. 2350 p.

14. Gastmans D. Hidrogeologia e hidroquímica do sistema Aquífero Guarani na porção ocidental da bacia sedimentar do Paraná [tese]. Rio Claro (SP): Universidade Estadual Paulista. Instituto de Geociências e Ciências Exatas; 2007. 238 p.

15. Araújo JC. Recursos Hídricos em regiões semiáridas: Instituto Nacional do Semiárido - INSA e Universidade Federal do Recôncavo Bahiano - UFRB, 2012. Capítulo 2, Recursos Hídricos em regiões semiáridas: estudos e aplicações; p 30-45.

16. Santos JS, Oliveira E, Massaro S. Avaliação da salinização de açudes no semi-árido brasileiro por ICPAES. Química Nova. 2000 Fev;23(4):453-456.

17. Ayres RS, Westcot DW. A qualidade da água na agricultura. (Tradução), Campina Grande (PB): Universidade Federal da Paraíba; 1991. 218 p.

18. Silva IN, Fontes L de O, Tavella LB, Oliveira JB, Oliveira AC. Qualidade de água na irrigação. Revisão da Literatura. Agropecuária Científica no Semi-Árido. 2011;7(3):01-15.

19. Richards LA. Diagnosis and improvement of saline and álcali soils. Washington D.C.: U.S. Salinity Laboratory; 1954. 160 p.

20. Cordeiro GG. Qualidade de água para fins de irrigação (Conceitos Básicos e práticas). Petrolina (PE). Embrapa Semi-Árido; 2001. 34 p.

21. Almeida MMM, Alexandre AMB, Araújo LFP, Figueiredo MCB, Rosa M de F. Qualidade das águas da bacia do rio Acaraú - CE para irrigação. In: Anais do XVII Simpósio Brasileiro de Recursos Hídricos, 2007 Nov 25-29; São Paulo - SP.

22. Mir A, Piri J, Kisi O. Spatial monitoring and zoning water quality of Sistan River in the wet and dry years using GIS and geostatistics. Computers and Electronics in Agriculture. 2017 Jan;135:38-50, doi:10.1016/j.compag.2017.01.022

23. Santos CEO. Qualidade da água do reservatório poção da Ribeira: uma avaliação com base em técnicas Estatísticas multivariadas e nos processos Geoquímicos de salinização [dissertação]. São Cristóvão (SE): Universidade Federal de Sergipe. Programa de Pós Graduação em Recursos Hídricos; 2016. 97 p.

24. SERGIPE, Enciclopédia dos municípios sergipanos. Secretaria de Estado do Planejamento. Aracaju (SE). Secretaria de Orçamento e Gestão - SEPLAG; 2014. 231 p. 
25. Fernandes CEM. Desempenho da barragem Poção da Ribeira face aos abalos sísmicos oriundos de uma pedreira próxima em exploração. In: Anais do XIX Seminário Nacional de Grandes Barragens, 1991, p. 35-42, Aracaju - SE.

26. COHIDRO - Companhia de Desenvolvimento de Recursos Hídricos e Irrigação de Sergipe. Perímetro irrigado Poção da Ribeira. In: Histórico dos perímetros, características geofísicas e demográficas. Sergipe, 2011. Disponível em: http://www.cohidro.se.gov.br Acesso em: ago. 2014.

27. Mendonça NS. Sustentabilidade e usos múltiplos da água da barragem Poção da Ribeira - SE [dissertação]. São Cristóvão (SE): Universidade Federal de Sergipe. Programa de Pós Graduação em Desenvolvimento e Meio Ambiente; 2013. 225 p.

28. APHA - American Public Health Association, Standard Methods for Examination of Water and Wastewater, 2012. Washington - DC.

29. US EPA - United States Environmental Protection Agency. Ptaff F. Method 300.7: Disolved Sodium, Amonium, Potassium, Magnesium, and Calcium in Wet Deposition by Chemical Supressed Ion Chromatography, 1986. Cincinnati - OH.

30. Möbüs G. QUALIGRAF. Programa para análises da qualidade da água: Fundação Cearense de Meteorologia e Recursos Hídricos; 2014. Fortaleza - CE. Disponível em http://www.funceme.br/qualigraf/ Acesso em: mar. 2015.

31. Piper AM. A graphic procedure in the geochemical interpretation of water analysis. Transactions American Geophysical Union. 1944;25:914-923, doi:10.1029/TR025i006p00914. 